\title{
Structural and Systems Approach to Central Representation of Motor Functions: Importance of State Dependent Reactions
}

\author{
HERBERT H. JASPER
}

\section{INTRODUCTION}

It was with considerable hesitation that I finally accepted the kind invitation of Vernon Brooks and the Organizing Committee of this Symposium to say a few words at the end giving some of my impressions of the presentations and discussion and reflections on the remarkable advances in our knowledge of motor systems that has occurred during recent years. I have been asked also if I would try to place some of these findings from experimental laboratories in the context of clinical experience with diseases and disorders of motor control. I would like to draw particular attention to the importance of state dependent reactions in which patterns of behavior are set up, even including spinal reflexes, by present programs depending on the general or directional reactive state of the organism.

The importance of reactive state is of course common knowledge to the clinical neurologists in relation to all forms of motor performance dependent upon alertness, attention, levels of consciousness, sleep, waking, and upon instructions and effort given by the patient. The mechanisms involved in these more general state dependent control systems however have received new dimensions during recent years through a number of refined neurophysiological studies describing changes in unitary responses and specific reflex activities dependent upon present reactive states. Microphysiological methods have been extended to neurophar-

From the Department of Physiology, Université de Montréal.

Reprint requests to Prof. H. H. Jasper, Départment de physiologie, Faculté de médecin, case postale 6208, Succursale A, Montréal, Canada H3C 3 T8. macology and neurochemistry in order to identify at the level of single cells and synapses, transmitter and modulator substances such as the biogenic amines which may establish particular reactive states as well as general states of awareness.

Most important, it seems to me, in research developments in recent years is the application of precise microelectrode techniques combined with computers to the analysis of the behavior of single cells and synapses in the central nervous system in normal unanesthetized animals during prescribed behavioral tasks and to a limited extent in man. The presentations in the present symposium have given examples of the importance and potentialities of these methods. When coupled with micropharmacology, making possible the analysis of chemical controls of single neurons and synapses throughout the central nervous system, the wealth and precision of new information regarding the participation of individual neurons in the mechanisms of motor control has advanced our knowledge at an ever increasing pace. Recent reviews and symposia have helped to make it possible to follow at least some of these studies.* With the technical possibilities now at our disposal, it is necessary to re-examine many of our traditional neurological concepts of mechanisms of motor control in the light of these new data.

\section{Functional Localization at the Unicellular Level}

Exploration of the CNS with microelectrodes in order to record the firing pattern of single nerve cells in experimental animals, and in man, during the past twenty-five years has continued to impress me with the functional specificity of single cells in either the unanesthetized or lightly anesthetized preparation. In sensory systems, either at the thalamic or especially at the cortical level, each cell appears to have an individual pattern of response in relation to its peripheral receptive field, whether it be punctate or patterned, large or small, simple or complex. At the cortical level single cells may be further specialized to respond only to other spacial or temporal features of the stimulus such as direction of movement, separate cells specialized for phasic changes in a stimulus ("on" or "off") and others specialized to detect sustained levels of intensity, i.e. dynamic or static features in the temporal domain.

It would appear from the familiar studies of Mountcastle and associates in the somatic sensory system, and Hubel and Wiesel in the visual system that classes of cells with similar functions, or topographical relations (body or visual field) were grouped together in radially oriented columns in the sensory cortex. The size and specificity of such columns depends, however, upon the precision and experimental definition of a specific function. For example, in the visual system there are very small columns, only $40-50$ $\mathrm{m} \mu$ in diameter in which each cell appears to be most sensitive to the angular position of a line in a restricted visual receptive field, the individual miniature columns being grouped into larger columns about 1

\footnotetext{
* Symposia and Reviews: Allen and Tsukahara (1974), Asanuma (1975), Brooks and Stoney (1971), Colloque C.N.R.S. (1974), Evarts et al. (1971), Evarts and Thach (1969), Golgi Centennial Symposium (1975), Granit (1966, 1970), Phillips, C. G. (1969, 1973), Phillips, M. I. (1973), Stein et al. (1973).
} 
$\mathrm{mm}$ in diameter in order that all $360^{\circ}$ of angular specificity can be represented for a given receptive field. If angle specificity is considered a functional unit, the miniature columns extend in sheets across the cortex for this function to be represented in different parts of the visual field. Within each miniature column, however, each cell encountered at different depths or layers from the surface has its own specific functional properties with overlapping but not identical receptive fields. Feature detection is "more complex" in upper layers than in deeper layers where most geniculocortical afferents terminate.

In non-striate visual cortex (18 and 19) (Hubel and Wiesel, 1965), and in infero-temporal visual cortex (Gross et al., 1972), cellular specificity appears to be just as great, but selectivity depends upon more and more complex "trigger" features of stimulus patterns, and less upon local receptive fields. The progression from relatively simple cells, to those with more and more complex feature selectivity depends upon the system of interconnections between simple and complex cell assemblies, single cells in the inferotemporal visual cortex receiving converging input from widely separated retinal areas first processed in the occipital cortex of both hemispheres.

This digression into the principles of hierarchical organization in the specific functional properties of single cells or unit cell assemblies in multiple cortical projections of the visual system may seem irrelevant to this symposium, but I believe the principles of hierarchical specificity of single cells or cell assemblies in motor systems may follow the same model.*

The old, much disputed, question of "muscle" or "movement" representation in motor cortex raised by Charles Phillips in his introductory lecture may become irrelevant in this context. The refinement of Asanuma's intracortical microstimulation technique (Asanuma, 1975) has made possible the demonstration of functional relations between a few pyramidal tract neurons and one or a few agonistic muscles. This does not imply, of course, that simple and more highly complex relations do not exist between these cell assemblies and overlapping groups of specific assemblies for many muscle groups involved in the execution of simple movements.

This is not an "either or" question, but rather a hierarchical system, in which many other cortical areas and subcortical sensorimotor systems are also involved, each with its special contribution. Unicellular specificity is acquired by its relation within a local functional module of closely interconnected neurons, the module gaining its specificity in relation to adjacent and distant modules in systems of ever increasing complexity, and interacting in closed and open loops with other sensorimotor systems throughout the neuraxis.

I would like now to turn to an example of complex functional localization at the single neuronal level from recent experiments of Mountcastle and associates on the parietal cortex (5 and 7) of the monkey (Mountcastle, 1975). Mounted in a restraining chair, a monkey was trained to point to a spot of light located in a fixed part of the visual field to be rewarded with a drink of orange juice. Once well learned, accurate movements were possible without visual guidance.

Microelectrode recording was then carried out in parietal areas 5 and 7 in search of cells responding in relation to this specific space oriented movement. In these areas the cells did not respond to the usual somatic sensory stimuli, nor to passive movements of the arm. Some, however, were activated only by a self initiated movement of the arm toward a fixed position in space. They did not respond to other self initiated movements of the same musculature. The importance of parietal cortex for body orientation in space is thus confirmed at the cellular level, and in relation to self initiated precise movements in space, independent of visual guidance.

Another interesting example was provided by Emilio Bizzi in his studies of single cells in frontal eye fields of the monkey during saccadic fixation and pursuit movements of the eyes (Bizzi, 1968). Certain cells responded only following saccads, while others were involved in the control of pursuit movements. Obviously cellular localization here was in relation to movements rather than with specific muscles involved, the saccadic movements being controlled by subcortical systems. In primary motor cortex, the larger PT cells are involved in the initiation of phasic movements, smaller cells more involved in tonic-postural sustained contractions.

\section{Unit Activity During the Establishment of a Conditioned Motor Response}

When we first began the study of the firing patterns of single cortical cells in the monkey during learned motor tasks at the Montreal Neurological Institute with Ricci and Doane (Jasper, Ricci and Doane, 1958,1960 ), we were primarily interested in conditioning rather than in the details of movement control itself (Fig. 1).

In these early experiments, carried out before computers were available, we recorded the activity of single cortical cells in visual, parietal, somatic sensory and motor, and frontal cortical areas during the establishment of a conditioning withdrawal response to a specific frequency of flashing light. The frequency coding of the conditioning stimuli enabled us to follow in the firing pattern of single cells to what extent the information containing the instructions for a given response was conveyed to the motor cortex involved in its execution. A delay period of 5-6 seconds was also introduced in order to assess the degree to which cells in the motor cortex are involved in the anticipation or presetting of the pattern of motor response as well as in its final execution.

It was found that single cells in all cortical areas explored were involved in special ways in the estab-

\footnotetext{
*Stephen Kuffler (1973) has written an interesting review of the single cell approach in the visual system for the Proctor Award Lecture to the Association for Research in Vision and Ophthalmology which is well worth reading in this context.
} 


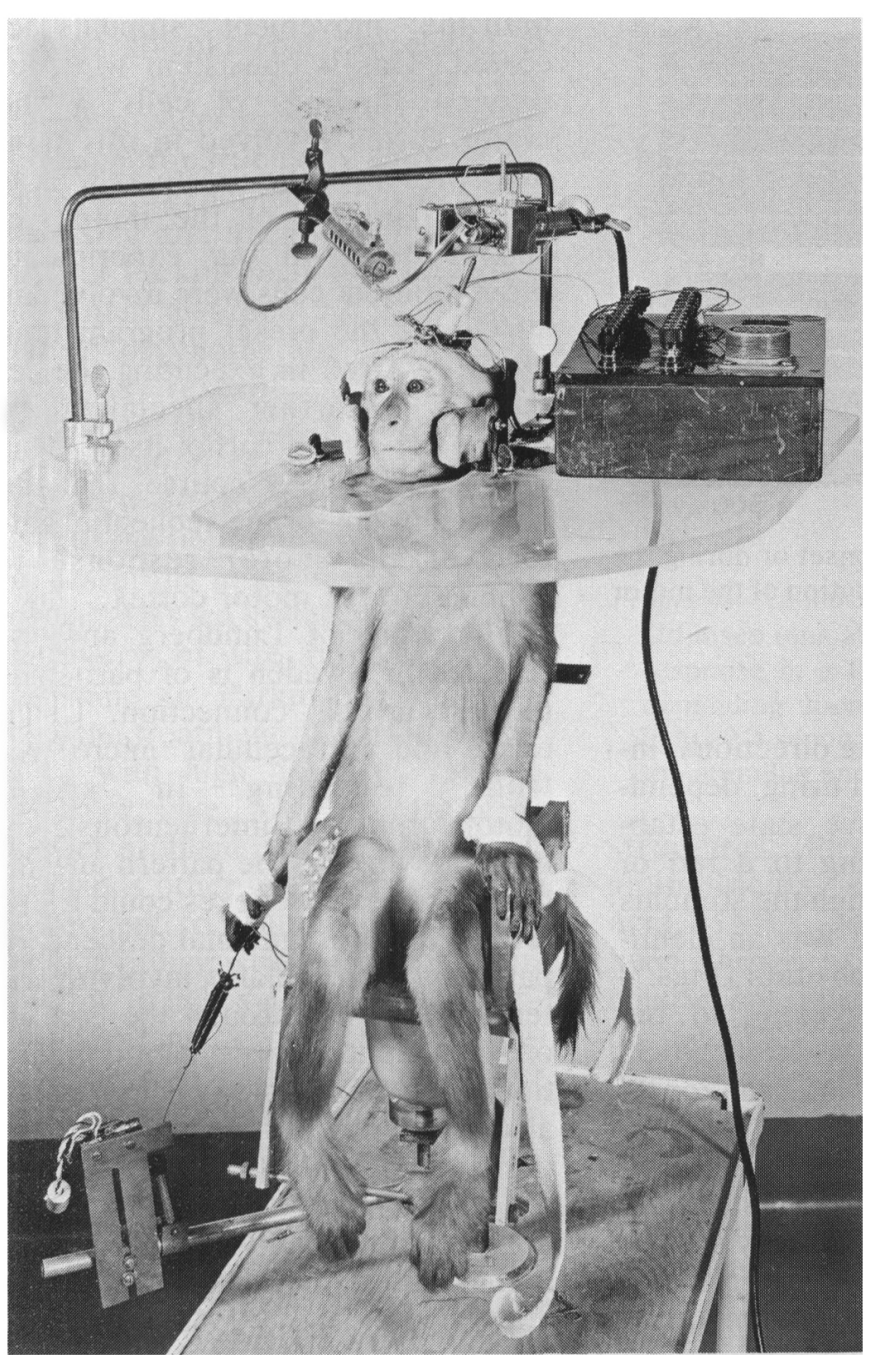

Figure 1-Monkey in restraining chair for microelectrode recording of the firing pattern of single cortical cells during conditioning of a shock avoidance reflex to the frequency of a flashing light as used in the early experiment of Jasper, Ricci and Doane $(1958,1960)$ described in the text. Not shown are E.M.G. recording electrodes and stroboscopic flash used for the conditioned stimulus.

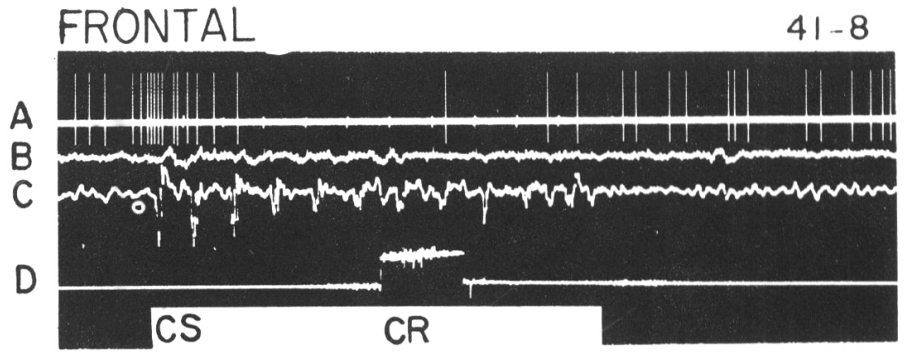

SENSORY $56-35$

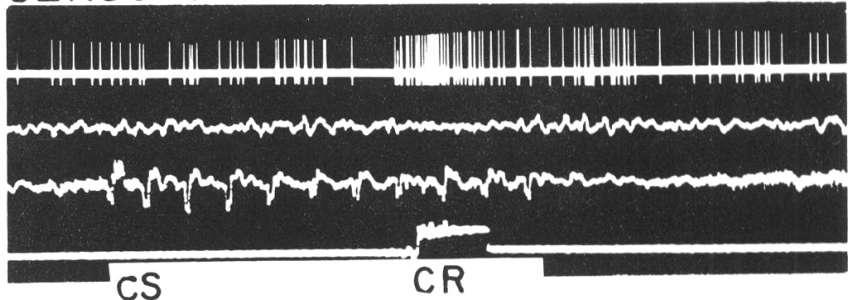

PARIETAL

$45-33$

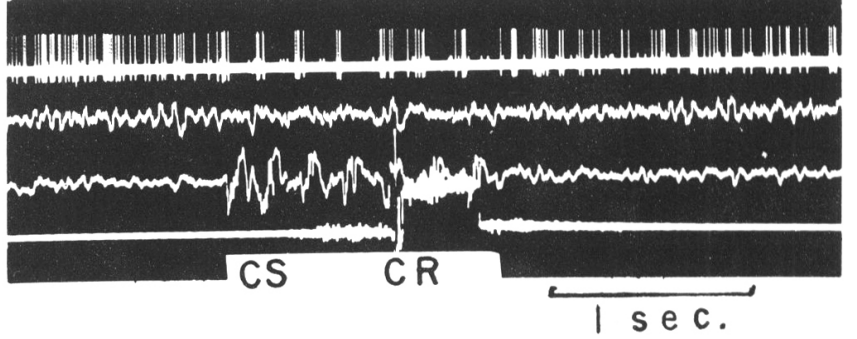

Figure 2-Samples of unit responses in frontal, somatic sensory, and parietal cortex after the establishment of a delayed conditioned avoidance response (CR in line $D$ of each tracing with superimposed E.M.G. from biceps muscle). Line B in each sample is the surface E.E.G. adjacent to the point of insertion of the microelectrode, and $C$ is the surface E.E.G. from visual cortex, recording evoked responses to the conditioning stimulus. Each area has its own pattern of response, the sensory area apparently only responding to sensory feedback from the response itself. Grouping of unit discharges at the flash frequency are shown in units of parietal cortex only to positively conditioned flash frequencies, being inhibited by differential unconditioned flash frequencies. lishment of this conditioned response. Evoked field potentials and unit discharges in the visual cortex were altered in a regular and predictive manner as the visual stimulus became of significance for a withdrawal response. Cells in the parietal cortex were entrained at the frequency of the conditioning stimulus which had been reenforced by an electric shock, and inhibited by unreenforced flash frequencies to which there was no response (Fig. 2). Cells in the somatic sensory cortex did not follow the flash frequency after conditioning, nor did they fire prior to the conditioned motor response, only during the response itself, and to passive movements of the limb involved.

In the motor cortex also the significant information in the frequency of the flash was not reflected in unit firing patterns. There were, of course, those cells, presumably PT neurons, which fired with mechanical regularity a fraction of a second before and during the E.M.G. record of the motor response itself, or were inhibited during the same period. Other cells in the same area, however, did not seem to be involved in the execution of the motor withdrawal response itself, but were involved in the instruction to carry it out, and in the holding or delay period before its execution (Fig. 3). However, the information upon which these instructions were based, namely the flash frequency, was not conveyed to the motor cortex.

It was in the parietal cortex that differential responses to the frequency of the conditioning stimulus would suggest its involvement in "decisive" or directive motor control. This would be in keeping with the recent work of Mountcastle on 


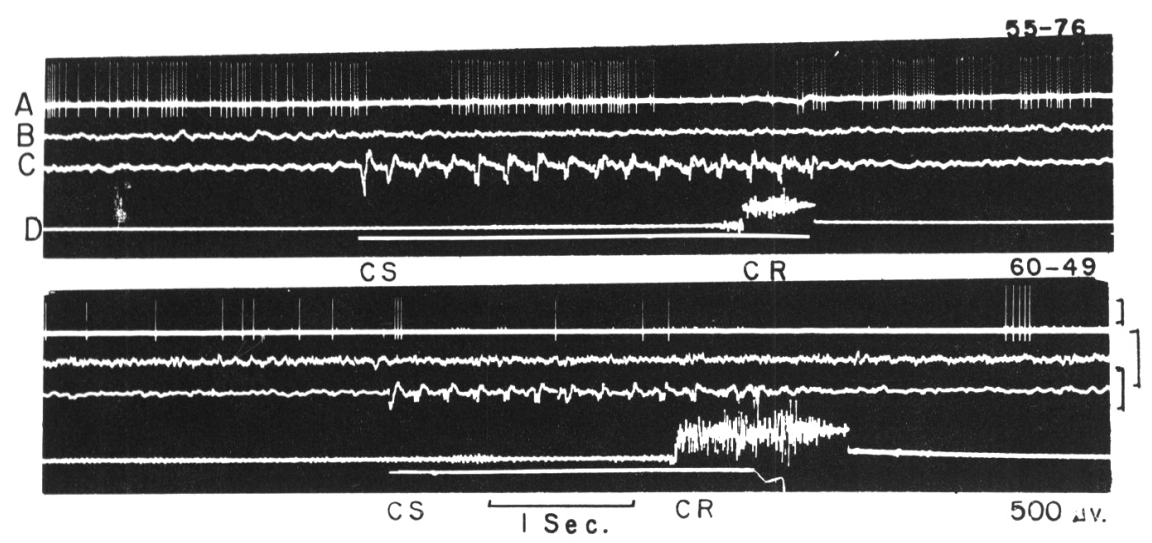

Figure 3-Samples of unit firing in motor cortex responding at the onset or during the delay period of the CR, though not apparently involved in the execution of the motor response itself.

parietal units firing only during self initiated spacially oriented movements, mentioned above. In our experiments, frontal cortical cells were also involved in the "command" and "holding" aspect of the motor response, though not in its execution, nor in the decision based upon information contained in the conditioning stimulus (see Fig. 2).

\section{Motor Control by Prior \\ Instruction and Reactive State}

More recent studies of responses in both PT and non PT neurons of the motor cortex in the monkey with accurate latency measurements under computer control (Evarts and Tanji, 1974) has provided new insight into mechanisms whereby preset patterns of rapid or reflex motor responses can be determined by prior instruction. In animal experiments "prior instruction" was established by conditioning techniques.

In Evarts' experiments, monkeys were trained to make flexor or extensor movements of the wrist in immediate response to a brief abrupt imposed change or "perturbation" in position of the hand, either flexion or extension. The "instruction" to flex or extend the wrist was given by red or green lights prior to the postural perturbation of the wrist. The direction of movement ("push or pull') to an identical stimulus was reversed depending upon whether a red or green light preceded it.

Both PT cells and non PT cells in the hand area of the motor cortex responded in opposite directions, increased or decreased firing, dependlished by conditioning to a red or green light, even though the stimulus for the reaction itself was an identical change in wrist position (Figs. 4 and 5). This might be expected, but the rapidity of this reaction, 20-30 msec, precluded the intervention of "voluntary" control. Since the original work of Hammond, described by Evarts (1975) in discussing his work, there have been many studies showing that relatively simple segmental reflexes can also be modified ming their reactive state. The speed of these preprogrammed reactions implies plasticity in even the more direct reflex circuits underlying motor control, not only in their "gain" or sensitivity, but also in the pattern of their motor response.

In the studies of Evarts and Tanji, E.M.G. records were also taken in order to measure simple stretch reflexes of the muscles involved in the wrist movements. They found that the shortest latency responses $(12$ $\mathrm{msec}$ ) were also modified by prior instruction, which had established a different reactive state for the monosynaptic stretch reflex, as well as for cells of the motor cortex. They also found that motor cortical cells showed consistent changes in their firing pattern within about 200 msec of the instructional stimulus (red or green light) and sustained this anticipatory response for $1-2 \mathrm{sec}$ ing upon the reactive state estabin a similar manner by preprogram- until the "movement" stimulus occurred. This is consistent with our previous findings of cells in the motor cortex involved in maintaining a preset reactive state as well as in the initiation of the motor response itself. In our experiments often different cells were involved in sustaining the preset program than those involved in executing the response, a further specialization within the motor cortex itself. This does not mean, of course, that the neural engram for the sequential pattern of the motor response is confined to the motor cortex.

The work of Lundberg and associates in Sweden is of particular interest in this connection. Using extra and intracellular microelectrode recording in spinal motoneurons and interneurons they have shown that the pattern and intensity of flexor reflexes could be altered by suprasegmental descending pathways, particularly involving interneurons and through the control of FRA input by presynaptic inhibition. They were able to demonstrate also, that an important part of these descending controls were mediated by descending serotinergic and noradrenergic pathways originating in the brain stem (Andén et al., 1966, a,b; Engberg et al., 1968, a,b; Jankowska et al., 1967, a,b and Lundberg, 1965).

L-Dopa administration in the spinal animal was found to depress short latency flexor reflexes, but to reveal (presumable by disinhibition) a markedly increased longer latency "tonic" multineuronal reflex which was not apparent before. This was probably due to increased release of noradrenaline from terminals of noradrenergic fibers which normally modulate spinal reflexes. This raises the question of the more general importance of the biogenic amines and other chemical substances in motor control at all levels of the CNS, especially in establishing state dependent reactions.

\section{Chemical Controls of Reactive States and Patterns of Response}

The importance of chemically controlled reactive states and even patterns of reaction, including disor- 
ders of motor control, dyskinesia, as well as hypokinesia as related to chemical control systems has been receiving widespread demonstration and support particularly with the advent of psychopharmacology. The surprising and unexpected development of Parkinsonian-like and other movement disorders as a complication of psychotherapy with drugs, such as reserpine and chlorpromazine, affecting the metabolism and liberation of the mono-amines first drew attention of pharmacologists to the importance of the monoamines in the mechanisms of motor control. This led systematically to the discovery of the importance of dopamine in Parkinson's disease. With the treatment of Parkinson patients with high doses of L-Dopa however, we are experiencing another problem in the development of various other forms of dyskinesia consequent to prolonged high level L-Dopa administration itself, thus bringing to light once again the critical importance of the chemical balance of transmitter or modulator substances for the proper functioning of central motor control systems (Calne et al., 1975).

The importance of state dependent reactions needs no emphasis for the neuroscientist or clinical neurologist. Tremors which disappear during sleep, or appear during intentional movement are familiar examples. Ataxia, dyskinesia, bradykinesia, tremors, dystonia, myoclonus, and stereotyped patterns of behavior are all known to be related in many instances to known or suspected chemically controlled reactive states, endogenous or drug induced. Neuroendocrine induction of complex behavior patterns are known to depend upon specialized neuronal systems, particularly in limbic and diencephalic regions.

It is now known that axonal terminals from specialized neuronal systems liberating either serotonin or noradrenalin are present throughout the CNS, including cerebral cortex, cerebellum, striatum and spinal cord. Dopaminergic systems of neurons may have important terminals in cerebral cortex as well as in the striatum and other subcortical
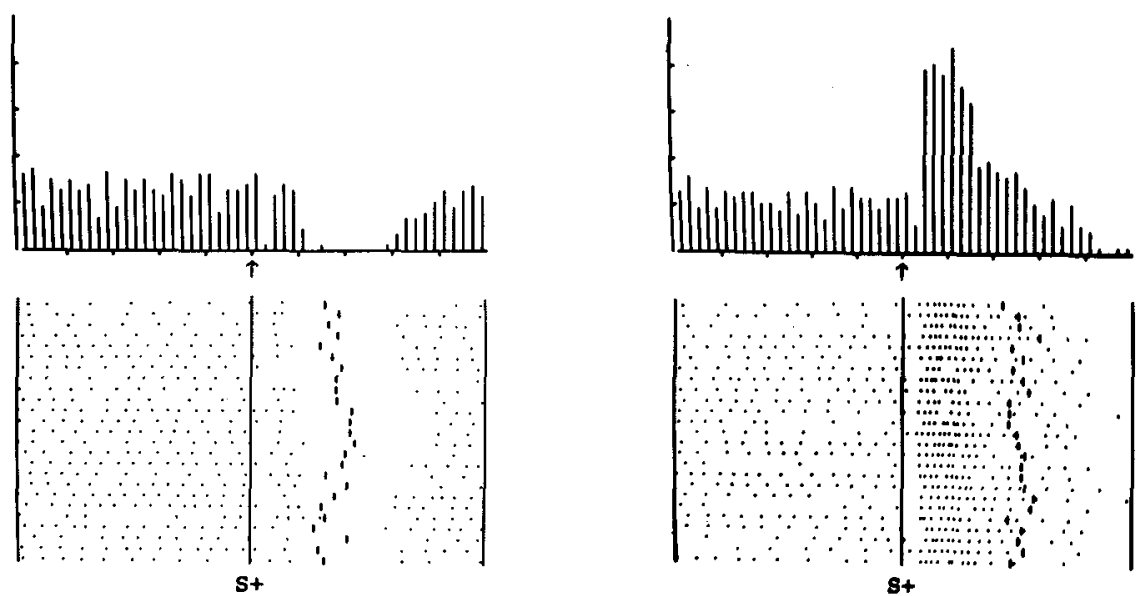

Figure 4-An illustration from the work of Evarts and Tanji (1974) showing histograms ( $20 \mathrm{msec}$ bins above) and raster displays (below) of complete reversal in pattern of response in a PTN to the same stimulus (slight flexor perturbarion of the hand) depending upon prior instruction to "push" or "pull" signalled by red or green lights $2-4$ seconds before. Note the change in background activity $500 \mathrm{msec}$ prior to the stimulus and the rapidity of the unit responses.

structures. Physiologically active amino acids, especially glutamic acid, GABA, and glycine have also been shown to have their specific anatomical substrate and transmitter or modulator functions throughout the CNS. Acetylcholine has also been shown to play a special role either as a transmitter or modulator of synaptic activity in relation to reactive states of sleep and waking, as well as in more specialized functions in the striatum, thalamus and spinal cord. All of these substances, and others likely to be discovered, are important candidates for chemical controls of reactive states in sensorimotor systems at various levels of the CNS. Their interaction and wide distribution are posing many difficult problems of interpretation, some of which are similar to those discussed above under the heading of "structural and systems approach to central representation of motor functions."

The demonstration that L-Dopa administration can alter the pattern of spinal reflexes even in the spinal animal, as shown by Lundberg and associates cited above would suggest that the effects of L-Dopa treatment of Parkinsonism are far more widespread than replacement of a dopamine deficiency in the striatum as originally presumed. Furthermore, it is now known that important changes in noradrenaline and serotonin metabolism are also produced by L-Dopa. Catecholamines appear also to regulate the metabolism of amino acids, including glutamic acid and GABA which in their turn are among the most important neurotransmitter or modulator substances in the CNS (Berl et al., 1975).

In recent unpublished work from our laboratories, in collaboration with Drs. J. de Champlain and T. Reader, we have shown that synaptic excitability in cerebral cortex can be modified depending upon the concentration of extracellular noradrenaline and dopamine, and that the liberation of these catecholamines are regulated in part by a specialized catecholaminergic projection system of subcortical origin. In previous studies, it was shown that acetylcholine was an important regulator of cortical excitability, especially in relation to states of sleep and waking and in relation to certain forms of epileptic discharge (Celesia and Jasper, 1966). It now seems likely that there is an important interaction between the cholinergic and catecholaminergic systems at the cortical level. ACh may be acting upon presynaptic NA terminals affecting the balance of these two substances in extracellular fluid. Increased liberation of ACh by sensory stimulation, for example, may cause a decrease in NA libera- 

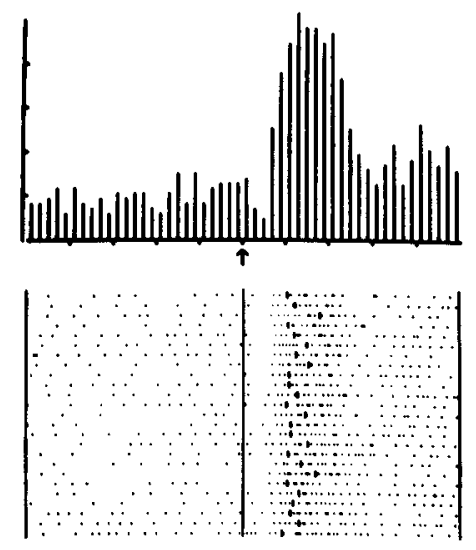

S+
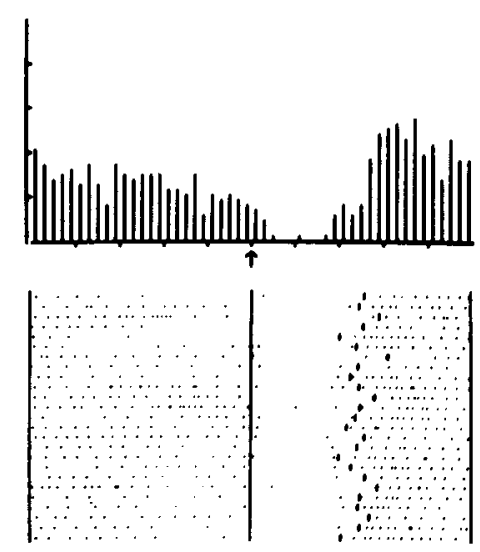

$\mathbf{s +}$

pressed by the use of highly sophisticated and expensive techniques to demonstrate at the unicellular level and with computer controlled measurements that the motor cortex is involved in the precise control of "voluntary" movements, and that these movements become dysmetric and slowly reversible when deprived of cerebellar control. However, the demonstration that motor cortical cells take part in rapid "reflex" responses, and that the cerebellum, thalamus, and parietal cortical cells may all participate in the initiation and programming of voluntary movements does have important consequences for clinical neurology. The demonstration of the importance of inhibitory controls, both pre- and postsynaptic, and the neurotransmitter substances involved in their mediation (amino acids and monoamines) may have immediate practical consequences for the better understanding and treatment of certain disorders of motor control in man. Dr. Richardson provided an interesting example in his contribution to this symposium, i.e. the importance of serotonin in the control of myoclonic seizures.

It was apparent from the present symposium that neuroscientists have much to learn from classical neurology as in the work of Gordon Holmes on the cerebellum and from the astute observations and theories of Hughlings Jackson on levels of representation and rerepresentation in the nervous system; the motor cortex being considered the mid level, and not the highest level of integration.

A "systems" approach to the understanding of motor control was already apparent in the work of Sherrington as well as in the theoretical interpretations of Hughlings Jackson. We now have the tools for the objective verification of many of these classical concepts, some of which have already been confirmed in remarkable detail (Phillips, Hughlings Jackson Lecture, 1973).

Many new concepts are also beginning to emerge, some of which have yet to be incorporated into clinical neurology, such as rapid cortical

\section{Fusion of Disciplines in the Neurosciences and its Impact on Clinical Neurology}

Traditional disciplinary divisions between the neurosciences clinical and basic scientists will certainly be necessary in the future.

Clinicians may not always be im- 
"reflexes" and the participation of cerebral cortex largely in "involuntary" or automatic control of movements, and the importance of subcortical systems for the initiation and patterning of so-called "voluntary" movements.

The histochemical identification of neurochemically distinct systems of neurons in the brain stem which project throughout the neuroaxis, including cerebellum, basal ganglia, and cerebral cortex, is a new and unexpected finding both to traditional neuroanatomy and to clinical neurology. Disorders, such as Parkinsonism, Huntington's Chorea, and certain forms of epilepsy, are now to be viewed not only in the light of the classical neuropathological findings, but in terms of defects in neurochemical control systems which may, in some instances be amenable to corrective or replacement therapy. The degree to which the selection of preset patterns of programs or behavior may depend upon neurochemical as well as structural features of assemblies of neurons has yet to be determined, but seems most likely. In addition, the establishment of temporary or more permanent patterns of synaptic organization in learning and memory may well depend also upon specific chemical substances capable of modifying not only synaptic functions but in the regulation of the metabolism of nerve cells.

Many of the most important old problems in clinical and experimental neurosciences still remain, however, still unsolved in spite of the remarkable advances in recent years. Mechanisms which determine conscious control or selection of patterns of motor response are still as mysterious as the nature of consciousness itself. In spite of the discovery of single cells which seem to respond exclusively during "voluntary" self initiated movements in thalamus, brain stem or cerebral cortex, it would be naive to assume that in such cells can be localized the mechanisms of conscious or willed movements.

Unit studies of conditioning have also failed to discover how the "engrams" of learned patterns of be- havior are formed, where they are stored, and how they are retrieved in finely coordinated temporal sequence either automatically or by the selective process of conscious attention.

Even the most complicated sequences of motor control, such as playing the pipe organ involving extraordinary precise timing of finger and feet movements in perfect bilateral coordination can be performed in what seems to be an automatic manner, without visual cues, and while the experienced organist may be carrying on a conversation with a bystander. We may learn much more about the control of single finger movements, or even single muscles or motor units, but an understanding of more complex control mechanisms is still far beyond our grasp.

\section{DISCUSSION}

Phillips described two types of responses which may occur with electrical stimulation of the brain: an immediate effect such as arrest of speech or movement and a second type of response where prolonged trains of stimuli evoke natural behaviour associated with goal-seeking drives. The latter type of response suggests a diffuse effect, but might conceivably be initiated if it were possible to carry out a very precise local injection of hormones or transmitter substances into an appropriate area of the brain. A major problem for neurology will be to show how these long-acting drives, which he referred to as "limbic neurology", are related to the more rapid responses of an animal to its constantly changing environment.

Wiesendanger referred to work by Lundberg and his associates who showed that the stepping responses produced by Schick and Grillner with electrical stimulation in the mesencephalic cuneiform nucleus could also be elicited by local injection of drugs to activate dopaminergic systems. This suggested that descending dopaminergic pathways are able to switch on or switch off certain motor programs.

York (Kingston) commented on long-term modulating influences versus short latency synaptic effects in diffuse monoaminergic systems. He stated that even in systems which have been studied extensively such as the nigrostriatal system, current views are almost certainly an over-simplification and that some of the transmitters probably have more than a single action.

\section{REFERENCES}

ALlEN, G. I. and TSUKAHARA, N. (1974). Cerebrocerebellar communication systems. Physiological Reviews, 54, 957-1006.
ANDÉN, N.-E., JUKES, M. G. M., LUNDBERG, A. and VYKLICKY, L. (1966a). The effect of DOPA on the spinal cord. 1. Influence on transmission from primary afferents. Acta physiologica Scandinavia, 67, 373-386.

ANDÉN, N.-E., JUKES, M. G. M. and LUNDBERG, A. (1966b). The effect of DOPA on the spinal cord. 2. A pharmacological analysis. Acta physiologica Scandinavia, 67, 387-397.

ASANUMA, H. (1975). Recent developments in the study of the columnar arrangement of neurons within the motor cortex. Physiological Reviews, 55, 143-156.

BERL, S., NICKLAS, W. J. and CLARKE, D. D. (1975). Coupling of catecholamines and amino acid metabolism in the nervous system. Golgi Centennial Symposium: Perspectives in Neurobiology. Ed. M. Santini, Raven Press, N.Y., 465-471.

BIZZI, E. (1968). Discharge of frontal eye field neurons during saccadic and following key movements in unanesthetized monkeys. Experimental Brain Research, 6, 69-80.

BROOKS, V. B. and STONEY, S. D. JR. (1971). Motor mechanisms: The role of the pyramidal system in motor control. Annual Review of Physiology, 33, 337-392.

CALNE, D., CHASE, T. N. and BARBEAU, A., editors. (1975). Advances in Neurology, Vol. 9, Dopaminergic Mechanisms. Raven Press, N.Y., pp. 427.

CELESIA, G. G. and JASPER, H. H. (1966). Acetylcholine released from cerebral cortex in relation to state of activation. Neurology, 16, 1053-1064.

COLLOQUE C.N.R.S. (1974). Motor Aspects of Behavior and Programmed Nervous Activities. Brain Research, 71, 189-575.

ENGBERG, I., LUNDBERG, A., and RYALL, R. W. (1968a). The effect of reserpine on transmission in the spinal cord. Acta physiologica Scandinavia, 72, 115-122.

ENGBERG, i., LUNDBERG, A., and RYALL, R. W. (1968b). Is the tonic decerebrate inhibition of reflex paths mediated by monoaminergic pathways? Acta physiologica Scandinavia, 72, 123-133.

EVARTS, E. V. (1975). Review: The Third Stevenson Lecture. Changing concepts of central control of movement. Canadian Journal of Physiology and Pharmacology, 53, 191-201.

EVARTS, E. V., BIZZI, E., BURKE, R. E., DeLONG, M., and THACH, W. T. (1971). Central control of movement. Neurosciences Research Program Bulletin, 9, 1-170.

EVARTS, E. V. and TANJI, J. (1974). Gating of motor cortex reflexes by prior instruction. Brain Research, 71, 479-494.

EVARTS, E. V. and THACH, W. T. (1969). Motor mechanisms of the CNS: Cerebrocerebellar interrelations. Annual Review of Physiology, 31, 451-498. 
GOLGI CENTENNIAL SYMPOSIUM: Perspectives in Neurobiology (1975). Ed., M. Santini, Raven Press, New York, pp. 668 .

GRANIT, R., Editor (1966). Muscular Afferents and Motor Control, John Wiley and Sons, New York, pp. 466.

GRANIT, R. (1970). The Basis of Motor Control, Academic Press, London, pp. 346.

GROSS, C. G., ROCHA-MIRANDA, C. E., and BENDER, D. B. (1972). Visual properties of neurons in inferotemporal cortex of the macaque. Journal of Neurophysiology, $35,96-111$.

HUBEL, D. H. and WIESEL, T. N. (1965). Receptive fields and functional architecture in two nonstriate visual areas (18 and 19) of the cat. Journal of Neurophysiology, 28, 229-239.

IVERSEN, L. L. (1975). Dopamine receptors in the brain. Science, 188, 1084-1089.

JANKOWSKA, E., JUKES, M. G. M., LUND, S., and LUNDBERG, A. (1967a). The effect of DOPA on the spinal cord. 5. Reciprocal organization of pathways transmitting excitatory action to alpha motoneurones of flexors and extensors.
Acta physiologica Scandinavia, 70, 369-388.

JANKOWSKA, E., JUKES, M. G. M., LUND, S., and LUNDBERG, A. (1967b). The effect of DOPA on the spinal cord. 6. Half-centre organization of interneurones transmitting effects from the flexor reflex afferents. Acta physiologica Scandinavia, $70,389-402$.

JASPER, H. H., RICCI, G. F., and DOANE, B. (1958). Patterns of cortical neuronal discharge during conditioned responses in monkeys. Ciba Foundation Symposium on the Neurological Basis of Behaviour, 277-290.

JASPER, H., RICCI, G., and DOANE, B. (1960). Microelectrode analysis of cortical cell discharge during avoidance conditioning in the monkey. Journal of Electroencephalography and Clinical Neurophysiology, Supplement No. 13 (The Moscow Colloquium on Electroencephalography of Higher Nervous Activity), 137-155.

KUFFLER, S. W. (1973). The single-cell approach in the visual system and the study of receptive fields. Investigative Ophthalmology, 12, 794-813.

LUNDBERG, A. (1965). Monoamines and spinal reflexes. Studies in Physiology. Springer-Verlag, Heidelberg, 186-190.

MOUNTCASTLE, V. B. (1975). The view from within: Pathways to the study of perception. The Johns Hopkins Medical Journal, 136, 109-131.

PHILLIPS, C. G. (1969). Motor apparatus of the baboon's hand. The Ferrier Lecture. Proceedings of the Royal Society, London, Series B 173, 141-174.

PHILLIPS, C. G. (1973). Cortical localization and 'sensorimotor processes' at the 'middle level' in primates. The Hughlings Jackson Lecture. Proceedings of the Royal Society of Medicine, London, 66, 987-1002.

PHILLIPS, M. I., Editor (1973). Brain Unit Activity During Behavior, Charles C. Thomas, Springfield, Ill., pp. 360.

SEEMAN, P. and LEE, T. (1975). Antipsychotic drugs: Direct correlation between clinical potency and presynaptic action on dopamine neurons. Science, 188 , 1217-1219.

STEIN, R. B., PEARSON, K. G., SMITH, R. S., and REDFORD, J. B., Editors (1973). Control of Posture and Locomotion. Advances in Behavioral Biology, 7, Plenum Press, New York, pp. 635. 